\title{
Persiapan Audit Sistem Manajemen Mutu (SMM) ISO 9001:2015 RSJD Dr. RM. Soedjarwadi Provinsi Jawa Tengah Pada Instalasi Rekam Medis
}

\author{
Chyu Yanuariska ${ }^{1}$, Rawi Miharti ${ }^{2}$ \\ Diploma III Rekam Medis Sekolah Vokasi UGM ${ }^{1,2}$ \\ chyu.yanuariska@mail.ugm.ac.id ${ }^{1}$, r4wimiharti@gmail.com²
}

\begin{abstract}
ABSTRAK
Latar Belakang: Rumah sakit melakukan perbaikan mutu, peningkatan kinerja dan penerapan manajemen risiko dilaksanakan secara berkesinambungan guna menjaga mutu pelayanan. Salah satu indikator standar penilaian tersebut adalah sertifikasi Sistem Manajemen Mutu (SMM) ISO 9001:2015. Di RSJD Dr. RM. Soedjarwadi pada bagian Instalasi Rekam Medis sudah melakukan persiapan dan audit SMM ISO 9001:2015 serta telah dinyatakan lulus audit SMM ISO 9001:2015.

Tujuan: Mengetahui persiapan audit Sistem Manajemen Mutu (SMM) ISO 9001:2015 RSJD Dr. RM. Soedjarwadi Provinsi Jawa Tengah pada Instalasi Rekam Medis serta kendala dalam persiapan tersebut.

Metode Penelitian: Jenis penelitian adalah penelitian kualitatif. Rancangan penelitian adalah studi fenomenologi. Subjek dalam penelitian ini adalah petugas pelaporan, koding, filing, dan kepala ruang instalasi rekam medis. Objek dalam penelitian ini adalah kegiatan persiapan yang dilakukan instalasi rekam medis dalam memenuhi klausul-klausul yang dipersyaratkan dalam SMM ISO 9001:2015. Teknik pengumpulan data dengan wawancara, observasi, dan studi dokumentasi.

Hasil: Persiapan yang dilakukan dibagi menjadi dua, yaitu persiapan teknis dan dokumen. Persiapan teknis adalah awareness dan pelatihan auditor internal, rapat instalasi rekam medis tidak dilakukan hanya koordinasi secara lisan, merapikan dan menata ulang ruangan dan filing, serta mengecek fasilitas. Persiapan dokumen adalah menyiapkan SOP-SOP, jobdesk-jobdesk, indikator mutu, form isu internal dan eksternal serta form peluang dan risiko yang disatukan menjadi satu folder dokumen ISO terintegrasi. Beberapa temuan audit internal tidak dilakukan perbaikan dan perbaikan yang dilakukan hanya penyisiran pada rak filing. Kendala persiapan yang dialami adalah keterbatasan waktu dan kurangnya sosialisasi serta komunikasi.
\end{abstract}

Kesimpulan: Persiapan audit Sistem Manajemen Mutu (SMM) ISO 9001:2015 dibedakan menjadi dua macam, yaitu persiapan teknis dan dokumen. Kendala persiapan yang dialami adalah keterbatasan waktu dan kurangnya sosialisasi serta komunikasi.

Kata Kunci: persiapan, audit, SMM ISO 9001:2015.

\section{ABSTRACT}

Background : Hospital repair the quality, increase the performance, and apply the risk management continously, need a performance assesment of service that were given in order to manage quality seriveces . One of standard indicator of the assesment is certification of Quality Management System (QMS) ISO 9001:2015. In RSJD Dr. RM. Soedjarwadi it is known that the medical record installation has done the audit preparation and audit of QMS ISO 9001:2015 and has passed QMS ISO 9001:2015.

Purpose : This research find out how audit preparation of Quality Management System (QMS) ISO 9001:2015 RSJD Dr. RM. Soedjarwadi Provinsi Jawa Tengah at medical record installation and problems in that preparation.

Research method : This research use descriptive research with a qualitative approach. This research planned by case study method. Subjects of this research are one of report officer, one of coding officer, one of filing officer, and the head of the medical record installation. Objects of this research are preparations thas has been done by medical record installation to complete klausul-klausul required in QMS ISO 9001:2015. Data were collected by interview, observation, and study documentation. Data validation use sources and techniques of triangulation.

Results : Preparations divided into two groups, there are technical preparation and documents preparation. The technical preparation is awareness and training of auditor internal, meeting of medical record installation not be done because the coordination is orally, fixing and rearranging the room and filing, and checking the facilities. SOP-SOP and the evidence, jobdescs, indicator of the quality, internal and external issues form and opportunities and risks form were collected into one document folder ISO integrated. Some problem in internal audit not to be repaired and improvement of internal audit's problems performed only scan on a filing rack. Problem of preparation is the limited time and lack of socialization and communication.

Conclusion : Preparations divided into two groups, there are technical preparation and documents preparation. Problem of preparation is the limited time and lack of socialization and communication.

Keyword : Preparation, audit, QMS ISO 9001:2015. 


\section{PENDAHULUAN}

Rekam medis adalah berkas yang berisikan catatan dan dokumen tentang identitas pasien, pemeriksaan, pengobatan, tindakan dan pelayanan lain yang telah diberikan kepada pasien (Permenkes 269 Tahun 2008). Rumah sakit adalah institusi pelayanan kesehatan yang menyelenggarakan pelayanan kesehatan perorangan secara paripurna yang menyediakan pelayanan rawat inap, rawat jalan, dan gawat darurat (UU RI No.44 Tahun 2009). Penyelenggaraan rekam medis di rumah sakit sangat penting mengingat bagian rekam medis merupakan salah satu gerbang terdepan dalam pelayanan kesehatan dan sebagai alat yang diukur dalam mutu pelayanan.

$$
\text { Masyarakat }
$$

menghendaki

pelayanan kesehatan yang aman dan bermutu, serta dapat menjawab kebutuhan mereka, oleh karena itu upaya peningkatan mutu, manajemen risiko, dan keselamatan pasien perlu diterapkan dalam pengelolaan rumah sakit dalam memberikan pelayanan kesehatan yang komprehensif kepada masyarakat. Untuk menjamin bahwa rumah sakit melakukan perbaikan mutu, peningkatan kinerja dan penerapan manajemen risiko dilaksanakan secara berkesinambungan maka perlu dilakukan penilaian kinerja terhadap pelayanan yang diberikan. Penyelenggara berkewajiban melakukan penilaian kinerja penyelenggaraan pelayanan publik secara berkala. Penilaian kinerja sebagaimana dimaksud dilakukan dengan menggunakan indikator kinerja berdasarkan standar pelayanan (UU RI No. 25 Tahun 2009). Hal tersebut dipertegas kembali kewajibannya di Provinsi Jawa Tengah bahwa dalam rangka optimalisasi pelayanan, penyelenggara wajib melakukan evaluasi penerapan standar pelayanan secara berkala setiap 1 (satu) tahun. Standar Pelayanan yang telah dilaksanakan wajib dilakukan peninjauan ulang setiap 3 (tiga) tahun (Perda Jateng No.7 Tahun 2015).

Evaluasi penilaian kinerja juga ditujukan untuk memberikan apresiasi kepada rumah sakit karena telah melaksanakan pelayanan prima atau sesuai kebutuhan masyarakat. Agar evaluasi penilaian kinerja tersebut dapat dilaksanakan secara obyektif, transparan, dan akuntabel, diperlukan suatu pedoman atau standar penilaian kinerja. Terdapat beberapa indikator untuk mengukur kualitas pelayanan publik. Salah satu indikator standar penilaian tersebut adalah sertifikasi Sistem Manajemen Mutu (SMM) ISO 9001 (Permen Pendayagunaan Aparatur Negara dan Reformasi Birokrasi RI No.1 Tahun 2015). Sistem Manajemen Mutu (SMM) ISO 9001 adalah suatu standar internasional untuk sertifikasi sistem manajemen mutu atau sertifikasi sistem manajemen kualitas. SMM ISO 9001 telah mengalami beberapa kali revisi dan revisi yang terbaru adalah SMM ISO 9001:2015.

Sertifikasi SMM ISO 9001:2015 menetapkan persyaratan-persyaratan dan rekomendasi untuk desain dan penilaian dari suatu sertifikasi sistem manajemen kualitas, yang bertujuan untuk menjamin bahwa organisasi akan memberikan produk (barang dan atau jasa) yang memenuhi persyaratan yang ditetapkan oleh badan dunia atau badan ISO. Peranan sertifikasi SMM ISO 9001:2015 cukup penting bagi rumah sakit mengingat dengan adanya sertifikasi tersebut menandakan bahwa rumah sakit telah memenuhi persyaratan-persyaratan yang telah ditetapkan dalam hal manajemen mutu pelayanan.

Hal ini dapat memenuhi kebutuhan pasien, dimana rumah sakit sudah dapat memberikan pelayanan yang berkualitas dan bermutu. Syarat terpenting untuk mendapatkan sertifikasi SMM ISO 9001:2015 tersebut, rumah sakit harus lulus audit SMM ISO 9001:2015 terlebih dahulu. Dalam rangka audit SMM ISO 9001:2015 tersebut diperlukan juga suatu persiapan yang matang. Persiapan tersebut dimaksudkan untuk memenuhi persyaratan-persyaratan yang telah ditetapkan sehingga rumah sakit akan dinyatakan lulus audit SMM ISO 9001:2015.

Berdasarkan hasil studi pendahuluan melalui wawancara dengan Kepala Ruang Instalasi Rekam Medis di RSJD Dr. RM. Soedjarwadi Provinsi Jawa Tengah pada tanggal 10 Januari 2017 
diperoleh informasi bahwa RSJD Dr. RM. Soedjarwadi Provinsi Jawa Tengah sudah melakukan persiapan untuk audit SMM ISO 9001:2015 dan sudah melakukan audit SMM ISO 9001:2015 yang dilaksanakan pada 21-22 November 2016 serta telah dinyatakan lulus audit SMM ISO 9001:2015.

Berdasarkan penjabaran diatas peneliti tertarik ingin melakukan analisis klausul-klausul persiapan audit SMM ISO 9001:2015 pada bagian Instalasi Rekam Medis di RSJD Dr. RM Soedjarwadi Provinsi Jawa Tengah. Alasan peneliti adalah ingin melihat lebih dalam lagi persiapan yang telah dilakukan. Dengan cara tersebut dapat diketahui kekurangan maupun kendala dalam persiapan tersebut sehingga untuk persiapan ke depannya hal-hal tersebut dapat diminimalisir mengingat audit SMM ISO 9001:2015 tersebut akan diperbarui setiap tiga tahun. Selain itu, diharapkan dapat menjadi acuan bagi rumah sakit lain yang ingin melakukan audit SMM ISO 9001:2015. Alasan peneliti memilih RSJD Dr. RM. Soedjarwadi Provinsi Jawa Tengah sebagai tempat penelitian adalah RSJD Dr. RM. Soedjarwadi Provinsi Jawa Tengah sering dijadikan rumah sakit tempat belajar atau studi banding bagi rumah sakit lain sehingga diharapkan akan menjadi masukan juga bagi rumah sakit lain. Selain itu, RSJD Dr. RM. Soedjarwadi berhasil meraih Penghargaan (Award) Citra Bhakti Kinerja pelayanan Publik dari Pemerintah Provinsi Jawa Tengah sebagai yang Terbaik ke I dalam Penilaian dan Pemeringkatan Kinerja Unit Pelayanan Publik tahun 2016 yang diterima tanggal 15 Agustus 2016 pada upacara peringatan Hari Jadi Provinsi Jawa Tengah. Kemudian peneliti mengambil judul yang lebih spesifik yaitu persiapan audit Sistem Manajemen Mutu (SMM) ISO 9001:2015 RSJD Dr. RM. Soedjarwadi Provinsi Jawa Tengah pada instalasi rekam medis.

\section{METODE}

Jenis penelitian adalah penelitian deskriptif dengan pendekatan kualitatif. Rancangan penelitian adalah studi Fenomenologi. Subjek penelitian diambil dengan menggunakan teknik purposive sampling (Notoatmodjo, 2012). Subjek dalam penelitian ini adalah petugas pelaporan, koding, filing, dan kepala ruang instalasi rekam medis. Objek penelitian ini adalah persiapan yang dilakukan untuk memenuhi klausulklausul yang di tetapkan dalam rangka persiapan audit SMM ISO 9001:2015 RSJD Dr. RM Soedjarwadi Provinsi Jawa Tengah pada Instalasi Rekam Medis. Teknik pengumpulan data yang digunakan adalah wawancara, observasi, dan studi dokumentasi. Analisis data, meliputi data reduction, data display, dan conclusion drawing/verification (Sugiyono, 2012). Pada penelitian ini disajikan secara naratif dari hasil wawancara kemudian hasil observasi dan studi dokumentasi disajikan dalam bentuk tabel.

\section{HASIL DAN PEMBAHASAN}

1. Mengetahui persiapan audit Sistem Manajemen Mutu (SMM) ISO 9001:2015 dengan memenuhi klausulklausul yang telah ditetapkan yang sudah dilakukan oleh instalasi rekam medis di RSJD Dr. RM. Soedjarwadi Provinsi Jawa Tengah

Persiapan audit Sistem Manajemen Mutu (SMM) ISO 9001:2015 yang dilakukan dibedakan menjadi dua, yaitu persiapan teknis dan dokumen.

a. Persiapan teknis

1. Pelatihan auditor internal dan awareness

Pelatihan auditor internal dilakukan untuk melatih beberapa staff yang nantinya akan menjadi tim auditor internal. Awareness dan workshop dilakukan untuk memperkenalkan staff terhadap klausul-klausul Sistem Manajemen Mutu (SMM) ISO 9001:2015. Kegiatan tersebut, khususnya bagi instalasi rekam medis menghasilkan dokumen terkait apa saja isu internal dan eksternal yang digunakan untuk memenuhi klausul 4.1 terkait isu internal dan eksternal yang ada di instalasi rekam medis. Selain itu menghasilkan dokumen terkait daftar peluang dan risiko yang ada di instalasi rekam medis serta cara instalasi mengatasinya yang digunakan 
untuk memenuhi klausul 6.1 terkait daftar peluang dan risiko serta cara instalasi mengatasinya (RSJD Dr. RM. Soedjarwadi Provinsi Jawa Tengah, 2015).

2. Rapat instalasi rekam medis

Instalasi rekam medis tidak melakukan rapat persiapan secara khusus, koordinasi yang dilakukan secara lisan dan penunjukkan tugas oleh kepala ruang.

3. Merapikan dan menata ulang ruangan dan filing, termasuk membuat denah rak filing dan penempelan nomor di rak

Kegiatan ini sekaligus memenuhi klausul 7.5.3 terkait pengendalian informasi terdokumentasi, yaitu instalasi rekam medis menjaga ruangan dan filing agar tetap rapi sehingga dapat meminimalisir berkas yang hilang atau terselip (RSJD Dr. RM. Soedjarwadi Provinsi Jawa Tengah, 2015).

4. Mengecek fasilitas

Kegiatan mengecek fasilitas bertujuan untuk memastikan fasilitas yang terdapat di instalasi rekam medis masih berfungsi dengan baik dan memadai. Kegiatan ini juga bertujuan untuk memenuhi klausul 7.1.3 terkait infrastruktur dan peralatan yang ada di instalasi rekam medis (RSJD Dr. RM. Soedjarwadi Provinsi Jawa Tengah, 2015).

b. Persiapan dokumen

1. Dokumen yang dipersiapkan secara khusus

Tabel 1. Dokumen Yang Dipersiapkan Secara Khusus

\begin{tabular}{|c|c|c|}
\hline No. & $\begin{array}{c}\text { Dokumen Yang } \\
\text { Dipersiapkan }\end{array}$ & $\begin{array}{l}\text { Pemenuhan } \\
\text { Klausul }\end{array}$ \\
\hline 1. & $\begin{array}{l}\text { Form terkait isu internal dan } \\
\text { eksternal beserta cara } \\
\text { mengatasinya }\end{array}$ & Klausul 4.1 \\
\hline 2. & $\begin{array}{l}\text { Daftar terkait peluang dan } \\
\text { risiko beserta cara } \\
\text { mengatasinya }\end{array}$ & Klausul 6.1 \\
\hline 3. & $\begin{array}{l}\text { SOP-SOP sebagai pedoman } \\
\text { melakukan kegiatan, } \\
\text { diantaranya: } \\
\text { 1. Analisis Kuantitatif } \\
\text { 2. Assembling } \\
\text { 3. Pengamanan Berkas } \\
\text { Rekam Medis (Saat } \\
\text { Terjadi Bencana) } \\
\text { 4. Pengisian Form RL } 3.7 \\
\text { 5. } \\
\text { Informed Consent }\end{array}$ & Klausul 7.5 \\
\hline
\end{tabular}

Tabel 1. (lanjutan) Dokumen Yang Dipersiapkan Secara Khusus

\begin{tabular}{|c|c|}
\hline & $\begin{array}{l}\text { Dokumen yang } \\
\text { Dipersiapkan }\end{array}$ \\
\hline
\end{tabular}

6. Kerahasiaan dan Keamanan Berkas Rekam Medis

7. Koding Diagnosis Penyakit Pasien

8. Koding Tindakan Kedokteran Pasien

9. Pemantauan Kerusakan Dokumen Rekam Medis

10. Pemusnahan Berkas Rekam Medis

11. Penanganan Nomor Rekam Medis Ganda

12. Penerimaan Asuransi Pasien Gawat Darurat

13. Penerimaan Asuransi Pasien Rawat Inap

14. Penerimaan Asuransi Rawat Jalan

15. Penerimaan Pasien Gawat Darurat Baru

16. Penerimaan Pasien Baru Rawat Jalan

17. Penerimaan Pasien Lama Gawat Darurat

18. Penerimaan Pasien Lama Pelayanan Penunjang

19. Penerimaan Pasien Lama Rawat Jalan

20. Penerimaan Pasien Baru Penunjang

21. Penerimaan Pasien Rawat Inap

22. Pengambilan Dokumen Rekam Medis

23. Pengembalian Dokumen Rekam Medis

24. Pengisian Buku Register Ranap

25. Pengisian Form RL 5.1

26. Pengisian Form RL 5.2

27. Pengisian Form RL 5.3

28. Pengisian Form RL 5.4

29. Pengisian Form RL 1

30. Pengisian Form RL 1.2

31. Pengisian Form RL 1.3

32. Pengisian Form RL 2

33. Pengisian Form RL 3.1

34. Pengisian Form RL 3.2

35. Pengisian Form RL 3.3

36. Pengisian Form RL 3.8

37. Pengisian Form RL 3.9

38. Pengisian Form RL 3.11

39. Pengisian Form RL 3.13

40. Pengisian Form RL 3.14 
Tabel 1. (lanjutan) Dokumen Yang Dipersiapkan Secara Khusus

\begin{tabular}{ccl}
\hline No & Dokumen yang & Pemenuhan \\
& Dipersiapkan & Klausul \\
\hline
\end{tabular}

41. Pengisian Form RL 3.15

42. Pengisian Form RL 4a

43. Pengisian Form RL $4 b$

44. Penyimpanan Dokumen Rekam Medis

45. Penyimpanan Dokumen Rekam Medis In Aktif

46. Permintaan Surat Keterangan Medis

47. Penomoran Dokumen Rekam Medis

48. Pelepasan/Pemaparan Rekam Medis

49. Resume Rawat Jalan

50. Identifikasi Pasien Jiwa Tanpa Identitas

51. Prosedur Mutu

4. Borang-borang rekam medis seperti:

Klausul 4.2, $4.4,7.4,7.5$

1. Buku ekspedisi

2. Buku register untuk mencatat berkas

3. Buku pendaftaran pasien rawat inap

4. Daftar jumlah tempat tidur kosong

5. Buku catatan berkas yang sudah di assembling

6. Buku stok formulir rekam medis

7. Buku bukti unit melengkapi kekurangan persyaratan ke bangsal

Buku SKM (Surat

Keterangan Medis)

5. Dokumen terkait tupoksi Klausul 5.3 petugas rekam medis

6. Indikator mutu / sasaran Klausul 6.2 mutu dan 7.3

2. Dokumen yang tidak dipersiapkan secara khusus

Tabel 2. Dokumen Yang Tidak Dipersiapkan Secara Khusus

\begin{tabular}{cll}
\hline No. & \multicolumn{1}{c}{$\begin{array}{c}\text { Dokumen Hasil } \\
\text { Observasi }\end{array}$} & $\begin{array}{c}\text { Pemenuhan } \\
\text { Klausul }\end{array}$ \\
\hline 1. & $\begin{array}{l}\text { Struktur organisasi } \\
\text { instalasi rekam medis }\end{array}$ & $\begin{array}{l}\text { Klausul 4.2, } \\
5.1 \text {, dan 7.3 }\end{array}$ \\
2. & Visi misi rumah sakit & Klausul 4.2, \\
& Kebijakan direktur & Klausul 4.3 \\
3. & $\begin{array}{l}\text { Kebtuk instalasi rekam } \\
\text { untuk }\end{array}$ & \\
\hline
\end{tabular}

Tabel 2. (lanjutan) Dokumen Yang Tidak Dipersiapkan Secara Khusus No Dokumentasi Hasil Pemenuhan Observasi Klausul

medis yang terdiri dari kebijakan umum dan khusus

4. Dokumen kebijakan Klausul 5.1, mutu 5.2, dan 7.3

5. Laporan kinerja Klausul 5.3 dan 6.2

6. Buku terkait evaluasi Klausul 6.3 dan analisis sasaran mutu tidak tercapai tidak ada karena yang melakukan langsung pihak manajemen

7. Dokumen bukti Klausul 7.1.2 kualifikasi terkait dan 7.2 pendidikan petugas rekam medis

8. Dokumen bukti Klausul 7.1.2 kompetensi petugas dan 7.2 rekam medis

9. Bukti perjanjian kerja Klausul 8.4 dengan pihak ketiga yang terdapat di pejabat pengadaan

10. Laporan evaluasi Klausul 8.4 kerjasama dengan pihak ketiga yang terdapat di tim pemeriksa

Kemudian terkait pemenuhan klausul 7.5 atau lebih tepatnya terkait SOP, terdapat beberapa revisi dan penambahan dari konsultan.

Tabel 3. SOP yang Direvisi

\begin{tabular}{|c|c|}
\hline No & SOP yang Direvisi \\
\hline 1. & Informed Consent \\
\hline 2. & Pelepasan/Pemaparan Rekam Medis \\
\hline 3. & $\begin{array}{l}\text { Pemantauan Kerusakan Dokumen } \\
\text { Rekam Medis }\end{array}$ \\
\hline 4. & nahan Berkas Rekam Medis \\
\hline 5. & $\begin{array}{l}\text { Penerimaan/Pendaftaran } \\
\text { Ranap }\end{array}$ \\
\hline 6. & $\begin{array}{l}\text { Pengamanan Rekam Medis (Saat } \\
\text { Terjadi Bencana) }\end{array}$ \\
\hline 7. & $\begin{array}{l}\text { Penyimpanan } \\
\text { Medis }\end{array}$ \\
\hline
\end{tabular}

Tabel 4. SOP yang Ditambahkan

\begin{tabular}{cll}
\hline No. & \multicolumn{1}{c}{ SOP yang Ditambahkan } \\
\hline 1. & Dokumentasi Rekam Medis & \\
2. & Informasi Pasien Rawat Inap & \\
3. & Informasi Pasien Rawat Jalan & \\
4. & Memeriksa Kelengkapan Rekam \\
& Medis \\
\hline
\end{tabular}


Waktu yang diperlukan perusahaan mulai dari tahap adopsi sampai sertifikasi sangat bervariasi, namun dibutuhkan waktu rata-rata antara 12-18 bulan (Yamit, 2005). Waktu persiapan sampai sertifikasi yang dilakukan instalasi rekam medis hanya tiga bulan sehingga terdapat beberapa ketidaksesuaian yang akhirnya diterima karena faktor keterbatasan waktu tersebut, diantaranya terkait revisi dan penambahan SOP yang akhirnya dibuat oleh konsultan dan kesekretariatan, tidak di sosialisasikan, serta beberapa juga tidak sesuai dengan instalasi rekam medis.

Seharusnya instalasi rekam medis tidak menerima begitu saja revisi dan penambahan SOP yang tidak sesuai tersebut dengan alasan keterbatasan waktu mengingat SOP tersebut akan dijadikan pedoman dalam memberikan pelayanan. Penambahan SOP juga harus disosialisasikan kepada petugas karena SOP adalah acuan dalam memberikan pelayanan sehingga sangat penting petugas mengetahui hal tersebut.

Audit internal adalah audit yang dilakukan oleh auditor yang berasal dari organisasi itu sendiri. Audit ini dilakukan biasanya untuk memastikan bahwa sistem telah dijalankan dengan benar, telah memenuhi standar yang diacu serta memungkinkan organisasi untuk melakukan improvement (tindakan perbaikan) yang akhirnya dapat memberikan gambaran kepada pihak manajemen tentang apa yang terjadi dalam organisasi (Zuhrawaty, 2009).

Berdasarkan klausul Sistem Manajemen Mutu (SMM) ISO 9001:2015 yaitu klausul 9.2 terkait audit internal menyatakan bahwa organisasi harus melakukan audit internal pada selang waktu terencana untuk memberikan informasi apakah sistem manajemen mutu sesuai terhadap persyaratan organisasi itu sendiri terkait sistem manajemen mutunya, persyaratan standar ISO 9001:2015, apakah efektif diimplementasikan dan dipelihara (RSJD Dr. RM. Soedjarwadi Provinsi Jawa Tengah, 2015).

Audit internal dilakukan tanggal 9 November 2016 secara silang. Beberapa temuan audit internal diantaranya: a. Beberapa belum ada SOP/IK

b. Beberapa belum ada revisi

c. Risiko kehilangan rekam medis

d. Kebutuhan alat yang kurang sesuai

e. Sumber daya yang kurang dan kurang kompetensi

Berdasarkan klausul Sistem

Manajemen Mutu (SMM) ISO 9001:2015

terkait klausul 9.3 tentang tinjauan manajemen, dinyatakan bahwa manajemen puncak harus meninjau sistem manajemen mutu organisasi, pada selang waktu terencana, untuk memastikan keberlangsungan kesesuaian, kecukupan, dan efektivitas. Output dari tinjauan manajemen harus mencakup keputusan dan tindakan yang berkaitan dengan peluang peningkatan terus-menerus, setiap kebutuhan untuk perubahan pada sistem manajemen mutu, termasuk kebutuhan sumber daya (RSJD Dr. RM. Soedjarwadi Provinsi Jawa Tengah, 2015).

Tanggapan instalasi rekam medis terkait temuan audit internal pada rapat tinjauan manajemen sebagai berikut:

a. Beberapa belum ada SOP/IK tersebut sudah ditambah konsultan pada waktu tinjauan lapangan

b. Beberapa belum revisi karena memakai protap lama dan sudah terdapat revisi dari konsultan

c. Risiko kehilangan berkas tersebut diadakan penyisiran yang masuknya kedalam tupoksi petugas filing.

d. Terkait kebutuhan alat tersebut yaitu rak yang kurang karena luas penyimpanan yang tidak memadai.

e. Sumber daya yang kurang dan kurangnya kompetensi sudah dibagi tugas dan diadakan pelatihan

Jadi terkait beberapa temuan audit internal, banyak yang di skip karena hanya berupa temuan minor atau kepala ruang instalasi rekam medis dapat memberikan sanggahan atau alasan terkait temuan tersebut. Tanggapan yang dilakukan hanyalah melakukan penyisiran kembali di ruang filing.

$$
\text { Berdasarkan klausul Sistem }
$$

Manajemen Mutu (SMM) ISO 9001:2015 pada klausul 10.3 terkait peningkatan berkelanjutan, organisasi harus mempertimbangkan hasil dari analisis dan evaluasi, serta keluaran tinjauan 
manajemen, untuk menentukan jika ada keperluan atau peluang yang harus ditangani sebagai bagian dari peningkatan berkelanjutan (RSJD Dr. RM. Soedjarwadi Provinsi Jawa Tengah, 2015). Meskipun telah lulus sertifikasi Sistem Manajemen Mutu (SMM) ISO 9001:2015, tetap harus melakukan peningkatan berkelanjutan dengan melakukan perbaikan pada temuan audit internal yang telah di skip mengingat temuan tersebut akan berpengaruh dalam pelayanan. Selain itu, agar tercapai peningkatan berkelanjutan seperti yang dipersyaratkan dalam klausul 10.3 dan terciptanya pelayanan yang berkualitas sesuai dengan apa yang dipersyaratkan dalam klausul-klausul Sistem Manajemen Mutu (SMM) ISO 9001:2015.

2. Kendala yang dialami dalam persiapan audit Sistem Manajemen Mutu (SMM) ISO 9001:2015 pada instalasi rekam medis di RSJD Dr. RM. Soedjarwadi Provinsi Jawa Tengah

Kendala yang dialami instalasi rekam medis adalah keterbatasan waktu dan kurangnya sosialisasi dan komunikasi. Ada banyak faktor yang dapat menyebabkan penerapan ISO 9001 tidak berjalan mulus. Diantara faktor yang paling dominan adalah:
a. Kurang Komitmen dari Top Manajemen

b. Tidak Ada Keterlibatan dari Karyawan

c. Koordinasi Antar Departemen yang Minim

d. Keterbatasan Waktu

e. Keterbatasan Sumber Daya Manusia (SDM)

f. Kurangnya Sosialisasi dan Komunikasi

Kendala yang dialami termasuk ke dalam kendala yang disebutkan tersebut (Umam, 2013). Terkait keterbatasan waktu tersebut karena persiapan hanya beberapa bulan sehingga mengakibatkan persiapan banyak dilakukan oleh kepala ruang instalasi rekam medis dengan dibantu tiga orang staff, beberapa SOP yang ditambahkan dan direvisi dilakukan oleh pihak konsultan dan sekretariat. Beberapa
SOP tersebut tidak sesuai tetapi instalasi tidak memberikan sanggahan karena keterbatasan waktu dan beranggapan akan di pergunakan dalam penilaian eksternal. Selain itu, revisi dan penambahan tersebut tidak di sosialisasikan dan beberapa temuan audit internal di skip.

Dengan keterbatasan waktu yang ada, seharusnya dapat mengoptimalkan petugas yang dimiliki dengan membagi tugas untuk melakukan persiapan dengan koordinasi yang matang, maksudnya tidak perlu rapat secara resmi untuk penjelasan klausul atau pembagian tugas dan pemantauannya tetapi dapat dilakukan sembari mengobrol pada waktu senggang saat bekerja. Hal tersebut juga akan lebih efektif karena lebih banyak tenaga yang digunakan dan dapat menjadi sarana sosialisasi terhadap petugas terkait klausul Sistem Manajemen Mutu (SMM) ISO 9001:2015 sekaligus penerapannya.

Kendala selanjutnya adalah kurangnya sosialisasi dan komunikasi. Awareness atau sosialisasi yang dilakukan hanya kepada beberapa orang yang termasuk dalam tim ISO yaitu perwakilan empat orang dari masing-masing instalasi sehingga petugas yang tidak ikut sosialisasi tersebut tidak mengetahui terkait Sistem Manajemen Mutu (SMM) ISO 9001:2015 beserta klausul-klausul terbarunya.

Penerapan Sistem Manajemen Mutu (SMM) ISO 9001:2015 diterapkan untuk meningkatkan pelayanan yang berkualitas sesuai yang dipersyaratkan dalam klausul-klausulnya. Oleh karena itu, penting bagi setiap petugas untuk mengetahui terkait hal tersebut mengingat mereka adalah pelaksana yang nantinya akan menerapkan sistem manajemen mutu tersebut dalam pelayanan. Sebaiknya dilakukan sosialisasi dalam lingkup instalasi agar petugas yang tidak menjadi tim ISO juga dapat mengetahui. Dengan begitu diharapkan akan terasa perbedaan pelayanan sebelum sertifikasi Sistem Manajemen Mutu (SMM) ISO 9001:2015 dan sesudahnya, dengan harapan pelayanan yang diberikan semakin berkualitas. 


\section{PENUTUP}

\section{A. KESIMPULAN}

1. Persiapan audit Sistem Manajemen Mutu (SMM) ISO 9001:2015 dengan memenuhi klausul-klausul yang telah ditetapkan yang sudah dilakukan oleh instalasi rekam medis di RSJD Dr. RM. Soedjarwadi Provinsi Jawa Tengah

Persiapan dibedakan menjadi dua macam, yaitu persiapan teknis dan dokumen. Persiapan teknis yang dilakukan diantaranya:

a. Awareness dan pelatihan auditor internal

b. Rapat instalasi rekam medis tidak dilakukan tetapi koordinasi secara lisan

c. Merapikan dan menata ulang ruangan dan filing termasuk membuat denah rak dan penempelan nomor di rak

d. Mengecek fasilitas

Persiapan dokumen yang dilakukan diantaranya:

a. SOP-SOP

b. Borang-borang atau bukti melakukan kegiatan

c. Jobdesk-jobdesk

d. Indikator mutu

Beberapa dokumen yang tidak dipersiapkan secara khusus tetapi termasuk dalam pemenuhan klausul diantarnya:

a. Struktur organisasi instalasi

b. Visi misi rumah sakit

c. Kebijakan direktur terkait instalasi

d. Kebijakan mutu

e. Laporan kinerja

f. Buku terkait evaluasi dan analisis sasasaran mutu tidak tercapai

g. Bukti kualifikasi terkait pendidikan petugas rekam medis

h. Bukti kompetensi petugas rekam medis

i. Perjanjian kerja dengan pihak ketiga

j. Laporan evaluasi kerjasama dengan pihak ketiga

Terdapat beberapa penambahan dan revisi SOP dari konsultan. Beberapa temuan audit internal tidak dilakukan perbaikan. Tindakan perbaikan yang dilakukan adalah penyisiran rak filing.

2. Kendala yang dialami dalam persiapan audit Sistem Manajemen Mutu (SMM) ISO 9001:2015 pada instalasi rekam medis di RSJD Dr. RM. Soedjarwadi Provinsi Jawa Tengah

a. Keterbatasan waktu

b. Kurangnya sosialisasi dan komunikasi.

\section{B. SARAN}

1. Petugas instalasi rekam medis sebaiknya tidak menerima begitu saja tambahan atau revisi SOP yang tidak sesuai mengingat itu akan dijadikan pedoman dalam pelayanan.

2. Rumah sakit sebaiknya tetap melakukan perbaikan secara berkesinambungan terhadap temuan audit internal yang telah di skip untuk peningkatan kualitas pelayanan.

3. Keterbatasan waktu yang ada, sebaiknya mengoptimalkan petugas yang dimiliki dengan membagi tugas untuk melakukan persiapan dengan koordinasi yang matang

4. Sosialisasi sebaiknya dilakukan dalam lingkup instalasi agar petugas yang tidak menjadi tim ISO juga dapat mengetahui terkait klausul-klausul ISO, persiapan yang dilakukan hingga temuan dan perbaikan karena ISO tersebut akan di terapkan selamanya dalam pelayanan di rumah sakit.

\section{DAFTAR PUSTAKA}

Notoatmodjo, S. (2012). Metodologi Penelitian Kesehatan. Jakarta: Rineka Cipta.

Peraturan Daerah Provinsi Jawa Tengah Nomor 7 tahun 2015 tentang Pelayanan Publik. Diakses dari www.elibrary.dprd.jatengprov.go.id pada 1 Desember 2016

Peraturan Menteri Kesehatan Republik Indonesia No. 269/MENKES/III/2008 tentang Rekam Medis. Diakses dari www.depkes.go.id pada tanggal 16 Oktober 2016

Peraturan Menteri Pendayagunaan Aparatur Negara dan Reformasi Birokrasi Republik Indonesia Nomor 1 tahun 2015 tentang Pedoman Evaluasi Kinerja Penyelenggara Pelayanan 
Publik. Diakses dari WwW.menpan.go.id pada 1 Desember 2016

RSJD Dr. RM. Soedjarwadi Provinsi Jawa Tengah. (2016). Klausul Sistem Manajemen Mutu (SMM) ISO 9001:2015. Klaten.

Sugiyono. (2012). Metode Penelitian Kuantitatif Kualitatif dan $R$ \& $D$. Bandung: Alfabeta.

Umam, K. (2013). Kendala dalam Menerapkan ISO 9001. www.konsultaniso.web.id. Diakses pada 24 Maret 2017

Undang-undang Republik Indonesia Nomor 25 tahun 2009 tentang Pelayanan Publik. Diakses dari wWw.kemendagri.go.id pada 4 Desember 2016

Undang-undang Republik Indonesia Nomor 44 tahun 2009 tentang Rumah Sakit. Diakses dari www.kemendagri.go.id pada 3 Desember 2016

Yamit, Z. (2005). Manajemen Kualitas Produk dan Jasa. Yogyakarta: Ekonisia Kampus Fakultas Ekonomi UII Yogyakarta.

Zuhrawaty. (2009). Panduan dan Kiat Sukses Menjadi Auditor ISO 9001. Jakarta: Buku Kita. 